\title{
Saber y adivinar. Las adivinanzas como juego de la criptificación y el desvelamiento
}

\author{
Knowing and Guessing. Riddles \\ as a game of encrypting and unveiling
}

\author{
Honorio VELASCO \\ (UNED) \\ hvelasco@fsof.uned.es \\ ORCID ID: 0000-0003-1462-1011
}

\begin{abstract}
This paper offers to the reader a number RESUMEN: El siguiente trabajo presenta al lector of popular texts which were used for teaching una serie de textos de carácter popular, los cuales Spanish. I suggest that, even these texts could appear fueron empleados para el aprendizaje del español. as simple games, such tongue-twister and riddles, Con esto, el autor propone que, incluso, aquellos they are relevant for teaching, not only Spanish as a textos que podrían parecer como mero juego, foreign language, but also some social issues. pueden adquirir un valor importante para la enseñanza - tanto de la lengua, como de ciertos parámetros sociales-, como son los trabalenguas y las adivinanzas.
\end{abstract}

KEYWORDS: Oral tradition, teaching, riddles, PALABRAS-ClAVE: tradición oral, enseñanza, tongue-twisters adivinanzas, trabalenguas

\section{EJERCICIOS LINGÜÍSTICOS}

No se descubre nada diciendo que los géneros de la llamada «tradición oral»son ejercicios lingüísticos. El aprendizaje de la lengua se facilita, estimula y refuerza con refranes, trabalenguas, chistes, adivinanzas, etc. No solo la comprensión, sino el dominio de estos es un indicador inequívoco de un excelente conocimiento y de una alta capacidad de expresión y uso de aquella.

Algunos escritores renacentistas españoles (los hermanos Valdés son un claro ejemplo) usaron específicamente textos de la tradición oral como modelo de la lengua (precisamente de la lengua «vulgar», término contrapuesto al latín, lengua culta). Curiosamente estos textos volvieron a aparecer en los manuales escolares mucho más tarde y, después del Romanticismo, esos mismos textos de la lengua «vulgar» fueron redescubiertos como literatura «popular».

Estos usos pedagógicos, aunque reveladores, solo contribuyen a subrayar una función metalingüística permanentemente activa en la tradición oral. Determinados géneros lúdicos son estrictamente juegos lingüísticos como los trabalenguas y las adivinanzas. Se diría que los primeros se proponen como ejercicios fonéticos y parecería como si la intencionalidad semántica fuera irrelevante. Unos tratan de provocar la 
pronunciación de fonemas, si se puede usar la expresión, «fonemas testigo», porque evidencian discapacidades, por ejemplo, la pronunciación de $/ R /$ en:

El perro de San Roque

no tiene rabo,

porque Ramón Rodríguez

se lo ha quitado.

Otros trabalenguas muestran, también, la reiteración y, sobre ella, la capacidad de discriminar conjuntos contrapuestos de fonemas. Algunos más desarrollan la formación de lexemas, mediante construcciones complejas a base de extensiones, adiciones, transformaciones reconocibles en todo caso, aunque carezcan aparentemente de sentido:

Érase una cabra ética, perlética, perlimpelambrética, perlúa

Y con la cabeza hocicuda,

que tenía un cabrito ético, perlético, perlimpelambrético, perlúo

y con el morro hocicudo.

No obstante, no se trata de meros ejercicios lingüísticos, pues no dejan de ser mensajes en una interacción social, que, proferidos, se atienen a un código cultural. Son un «juego». Principalmente, son un juego infantil, un entretenimiento. Parece como si incitasen al error y por lo mismo indujeran una fuerte motivación para el aprendizaje.

Los trabalenguas también se podrían considerar no solo como ejercicios de pronunciación para aprendices de la lengua, sino también como ejercicios de pautas de comunicación y de discriminación para hacer evidentes la desigualdad y la diferencia.

Nunca carecen de sentido, dado que las reglas del juego son capaces de otorgar sentido precisamente a palabras absurdas, porque son difíciles de pronunciar correctamente. Por ejemplo, en condiciones de secuencia reiterativa de contrastes fonémicos, como en:

En el jardín del rey entré a coger calongé, calangí, calangelé; díganle a mi tío calangelero que me haga un calangelí de este madero.

Además, las reglas incluyen la obligación de proferirlas con rapidez, como si fueran frases del discurso normal. Y de hacerlo en público, con la expectativa por parte de los demás del fallo. Caben intentos repetidos, pero la ejecución correcta no siempre se logra con la repetición indefinida. No pocos jugadores dejan por imposibles determinados trabalenguas.

Por otra parte, se descubre que el éxito en realidad no consistía más que en estar a la altura de los demás. La exhibición de muchas habilidades tradicionales es fundamentalmente una prueba de integración y no siempre una competencia. En algún sentido, quienes no los superan sistemáticamente quedan marcados - las dislalias y otros trastornos del habla quedan explícitos-, pero quienes los superan se sitúan simplemente en la normalidad.

De esa manera se muestra que una de las formas del saber (lingüístico) consiste en dar continuidad y fluidez al discurso. Quienes se traban con las palabras, quiebran el 
discurso, lo interrumpen. Estos juegos intensifican esa situación. La habilidad de llegar hasta el fin y de dar fluidez al discurso se pone a prueba, se adquiere con estos aprendizajes y es sancionada como un saber.

Si los trabalenguas se figuran como ejercicios fonéticos, las adivinanzas aparecen como ejercicios retóricos. Algunas pueden tener algo de trabalenguas, pero fundamentalmente son propuestas y dirigidas a la mente, al ingenio. A veces, son descripciones sorprendentes; otras, enumeraciones incompletas de elementos componentes; otras, construcciones paradójicas que parecen poner trabas al raciocinio, etc. En este sentido, a diferencia de los «traba-lenguas» se encuadrarían dentro de un conjunto genérico aproximadamente análogo al juego designado por el término «rompecabezas».

Si se tomaran las adivinanzas como ejercicios retóricos, se podría descubrir en ellas todo un amplio espectro de los tropos y las figuras: metáforas, sinécdoques, metonimias, hipérboles, prosopopeyas, calambures, antítesis, quiasmos, etc. Y, si se tomara todo este conjunto de tropos y figuras como perífrasis de palabras y de frases literales que se refieren a objetos o secuencias de acciones, es decir, como transformaciones codificadas de la realidad percibida, entonces, elevándose desde el análisis semántico — que en cierto modo es reductivo-, se encontraría su relevancia como enunciados poéticos.

La poesía como transformación de la realidad se descubre con los diferentes tropos y figuras, además, se revela un peculiar modo poético: la encriptificación, que resulta ser característico de las adivinanzas y de todos esos pequeños discursos afines que reciben, por un lado, el intrigante nombre de «enigmas» y, por otro, el insignificante nombre de «acertijos». Tanto unos como otros no se toman aquí tan solo como textos, sino como mensajes en una interacción social codificada culturalmente como «juego».

Adivinar no fue solo y no lo es ahora un juego infantil, pues también los adultos suelen realizarlos como juegos de entretenimiento, donde se distinguen dos papeles nítidamente marcados: el de quien formula la adivinanza y el de quien o quienes aceptan resolverla. Papeles que, sin embargo, no se sitúan en una posición de igualdad, sino que les diferencia el conocimiento previo, el de la pregunta y, sobre todo, el de la respuesta. Un conocimiento que genera dependencia, poder. Así que les diferencia el saber y con el saber, el poder.

Pese a la homonimia, los papeles del juego de las adivinanzas no son del todo equivalentes a los de las prácticas de la adivinación. En esta son los legos quienes formulan las preguntas y solo los sabios, los adivinos, los que proporcionan las respuestas. En las adivinanzas son los sabios los que formulan las preguntas e, igualmente, sabios serán los que acierten con las respuestas.

Tampoco se descubre nada diciendo que las adivinanzas son algo más que un juego inocente. La vieja historia sobre la muerte de Homero, incluida entre los fragmentos atribuidos a Aristóteles y, naturalmente, el enfrentamiento entre Edipo y la Esfinge, profundizan en el desasosiego de involucrarse en un juego de preguntas para las cuales puede no encontrarse respuesta, a no ser que las proporcione quien las formuló, pero eso implica - y ha de ser subrayado- dependencia de él.

El inocente juego de las adivinanzas tiene como contenido un discurso, donde están comprometidos los contendientes. Se trata de un discurso — un diálogo- que no concluye hasta que no se otorga la respuesta. Es un discurso que prende, que ata. Si no se da la respuesta, entonces queda incompleto, inacabado, pendiente. Y quien aceptó el juego en el papel de responder y no es capaz de hacerlo queda posiblemente atrapado en 
un discurso derivado, interior o en todo caso solipsista — descrito mediante la expresión «darle vueltas y vueltas»-, pero sobre todo prendido, a expensas de que quien propuso la adivinanza, condescendiente, termine por revelar la respuesta y de esa manera le libere.

En algo las adivinanzas se aproximan a la adivinación: en un cierto poder que deriva del saber, pero les distingue marcadamente el contenido. La adivinación se adentra en el futuro y en el misterio, en tanto que las soluciones de las adivinanzas versan sobre cosas cotidianas, cosas del entorno próximo, domésticas, cercanas, usuales, manidas. Cosas tales como pimiento, reloj, culebra, carbón, avellana, gallo, buey, pino, loro, nuez, bellota, colmena, huevo, cuaresma, devanadera, rosario, cañas, cebolla, sombra, granado, grillo, chispas, ojos, granada, flor de campanilla, nubes, etcétera ${ }^{1}$. Asimismo, las adivinanzas describen acciones tales como amasar el pan, cerrar una puerta, coser, meter el anillo en el dedo, llenar un saco de paja, etcétera. Las soluciones de estas últimas adivinanzas no suelen aparecer en las colecciones impresas seguramente porque los enunciados parecen referirse a actos sexuales. Cosas y acciones usuales y, en todo caso, palabras llanas y claras, que no serían en absoluto objeto de adivinación, a no ser que hubieran sido transformadas poéticamente por medio del lenguaje y sus mágicos recursos. En esto se descubre qué capacidad transformadora tiene la poesía y cuanto tiene de saber: un poderoso saber que consiste precisamente en la construcción y reconstrucción de la realidad.

\section{DE LA ESTRUCTURA DE LAS ADIVINANZAS A LOS MODELOS Y ESTRATEGIAS DEL JUEGO}

Una indagación sobre la estructura de las adivinanzas parece asumir la idea de la existencia de formas canónicas, pero de hecho en este «género» se recortan los perfiles de variadas y heterogéneas «especies»:

- cuentos de adivinanza,

- colmos (¿Cuál es el colmo de un...?),

- que le dijo («¿Qué le dijo un... a un...?»)

- parecidos («iEn qué se parece un... a un...?»)

- diferencias («¿En qué se diferencia a un... de un...?»)

- averiguaciones de parentesco:

Yo los sesos me devano y de pensar me vuelvo loca, la suegra de mi cuñado, ¿qué parentesco me toca? Mi madre.

- traducciones burlescas:

¿Cómo se dice perro con farol en chino?

Kan kon kinké.

- preguntas sobre cualidades o características extremas:

¿Cuál es el nombre más corto?

\footnotetext{
${ }^{1}$ Esta enumeración es sólo un fragmento de la lista de soluciones en la colección de adivinanzas infantiles que formó, a mediados del siglo XIX, Fernán Caballero.
} 
Ni-casi-o.

- Preguntas con pega, burlescas o humorísticas:

¿Dónde tienen las mujeres el pelo más rizado?

En África.

¿Cómo se meten cuatro elefantes en un seiscientos?

Dos delante y dos detrás.

¿Cuándo tiene la oveja más lana encima?

Cuando la monta el carnero.

- Definiciones humorísticas:

¿Qué es una oreja?

Sesenta minutejos.

- Cálculos con pega:

De veinte patos metidos en un cajón, ¿cuántas patas y picos son?

Seis.

¿Cuánto valen dos docenas y media de sardinas, a peseta y media la sardina y media? 30 pesetas.

- Falsos dilemas o ficticias situaciones desesperadas.

Se pueden agregar a esta lista las charadas y toda una amplia serie de formulaciones que requieren para su expresión la escritura como los crucigramas, las sopas de letras, entre otros.

Las adivinanzas se formulan, también, en lenguaje gestual o por medio de representaciones gráficas. Parece como si la indagación sobre la estructura se tornara incómoda ante tanta variedad. Una primera estrategia es abordarla en su amplitud postulando una estructura tan general y vaga como la que aparece cuando se recuerda que se trata de un discurso formado por preguntas y respuestas.

El juego de las adivinanzas corresponde al juego más básico del preguntar y responder, que emplea una de las formas del discurso dialogado. Aquél que es construido por locutor y audiencia, en tanto que interlocutores con papeles complementarios, de forma que a un primer enunciado en forma interrogativa se exige que se le responda; y en un segundo enunciado aseverativo, con el que se completa y cierra el discurso.

Seguramente la fascinación por los textos, a veces tan finamente compuestos, ha llevado en ocasiones a desdeñar las respuestas, pero, por supuesto, no cabe hacerlo - aun en el caso de que fueran arbitrarias-, pues, de lo contrario, se desvirtuaría el discurso y, lo que es tanto o más importante, el juego. Las aproximaciones más clásicas hace tiempo desvelaron en las adivinanzas una estructura no tan vaga y abstracta como la anterior, aunque igualmente formal, distinguiendo en las adivinanzas algunos enunciados tales como: 
1) fórmula introductoria o fórmula interrogativa, por ejemplo: «Adivina, adivinanza»o «Qué es cosa y cosa»o «Cosiqués, cosiqués» o «¿Cuál es?», «¿Cuándo tiene?» y otras fórmulas no tan frecuentes como:

Estudiante que estudias

en libros de Filosofía,

decidme.

Estas fórmulas definen el código del discurso y del juego en el que se involucran los participantes;

2) un conjunto de proposiciones — al menos una- que designan de forma no explícita uno o varios aspectos o rasgos de objetos, acciones o situaciones;

3) a estas dos a veces se añaden otras fórmulas que estimulan al desafío, establecen un plazo de resolución o prometen reconocimiento o denigración públicas según se acierte o no (por ejemplo, «[...] y el que no lo sepa, bien tonto es», «[...] ¿a que no me lo aciertas en un año?»). Todo ello es parte del discurso que profiere el que plantea la adivinanza;

4) y una respuesta, que se entiende correspondiente y adecuada a las proposiciones dadas y que debe ser aportada por quien aceptó su planteamiento.

Esta serie de secuencias recoge con claridad la condición de juego. Pero solo la (2) y la (4) están presentes en todas las ocasiones, de forma que el código se establece en el discurso previo y está sobreentendido; aunque podría estar igualmente marcado por determinados rasgos formales de las proposiciones en la secuencia (2) y, en todo caso, son fácilmente reconocidos por familiaridad con otras aparecidas en experiencias anteriores. Y, si solo las secuencias (2) y (4) bastan, es decir, si son ellas las que integran el núcleo de la estructura, en el fondo todo queda otra vez en un juego de preguntas y respuestas.

Naturalmente, no todo juego de preguntas y respuestas es un juego de adivinanzas, pero claramente el género puede extenderse por ese sendero en forma que pudiera parecer indefinida. Todorov ha intentado sortear este peligro postulando una relación de sinonimia entre el enunciado que se formula en pregunta y la respuesta (1978: 249). Lo que de hecho implica ya una configuración más sustantiva de la estructura, la de una definición. Es decir, toda adivinanza vendría a ser una definición en busca de un nombre ${ }^{2}$.

El dibujo de esta estructura no es tan vago, sino que sugiere un modo de relación entre pregunta y respuesta, la equivalencia (sinonimia, en términos semánticos) entre dos enunciados que podrían ser descritos como una frase o conjunto de frases y un nombre o un predicado y un sujeto. Esta relación, sin embargo, abandona ya el compromiso de abordar la heterogeneidad de los mensajes que suelen englobarse en este género y postula la existencia de una forma canónica, para la cual únicamente habría que reservar el término de «adivinanza».

No obstante, no es del todo cierto que toda adivinanza sea una definición en busca de un nombre. No todo enunciado formulado como pregunta es una definición, ni toda respuesta es un nombre. En vez de una definición a veces se proponen relaciones o «problemas» que demandan explicaciones y las respuestas pueden ser un objeto, una acción o una situación designados con palabras o las palabras en cuanto tales. Y, si son

${ }^{2} \mathrm{Al}$ contrario de las definiciones que aparecen en los diccionarios, por otro lado, susceptibles de ser formuladas con arreglo al juego de preguntas y respuestas, pero la pregunta conllevaría el enunciado del nombre y se pediría como respuesta su definición. 
palabras, pueden ser un nombre o un verbo, pueden ser una frase o una serie de frases; o pueden ser una letra, un conjunto de letras o un número, entre otros.

Todo ello introduce un fondo notable de ambigüedad. El intento de reducción a una forma canónica conlleva un uso restringido del término «adivinanza» que solo podría aplicarse con propiedad a los mensajes que se atuvieran a esta forma. Eso obliga a realizar una distinción precisa entre los términos enigma, adivinanza y acertijo ${ }^{3}$. Se reserva el primero, enigma, para enunciados de autor elaborados generalmente en forma estrófica compleja, como los que cultivaron no pocos autores españoles renacentistas y del Siglo de Oro, como Pérez de Herrera en Proverbios morales y consejos christianos (1733) o el propio Cervantes en La Galatea (1584). El segundo, adivinanza, se aplica a enunciados populares, anónimos, elaborados generalmente en forma estrófica simple. Y el tercero, acertijos, a enunciados también populares y anónimos, elaborados en prosa y de contenido extremadamente variado.

En cierto sentido los tres términos adivinanza, enigma y acertijo connotan contenidos relativamente distintos. Se insinúa que los enigmas remiten a las graves cuestiones de la existencia humana y a los profundos misterios del universo; las adivinanzas remiten a la complejidad de las relaciones sociales y al mundo de objetos e intereses de las personas adultas; los acertijos parecen, sin embargo, intrascendentes juegos de niños y de adultos burlones y ociosos. Pero los rasgos formales aducidos para justificar las diferencias no son demasiado consistentes.

Con estos tres términos resulta extremadamente difícil realizar una clasificación coherente y presumiblemente con solo ellos no se podría completar una clasificación omnicomprensiva para todo un amplio y extremadamente heterogéneo conjunto de enunciados que podría extenderse indefinidamente.

Por otro lado, las indagaciones sobre la estructura de las adivinanzas no dicen bastante, simplifican demasiado lo que es el juego. Debería sorprender que no haya apenas estudios de campo sobre el juego de las adivinanzas (el de Brandes [1980] sobre Monteros es una buena excepción), habiendo tantas colecciones impresas de ellas. La variabilidad de formas de juego puede ser amplia, pero habrá que asumirla cuando se disponga de suficientes datos etnográficos.

No obstante, algunos apuntes indican, aunque sea provisionalmente, lo siguiente: como juego social, se trata de un juego actualmente no muy frecuente, pero debió serlo más en otros tiempos ${ }^{4} \mathrm{y}$, en todo caso, como muchos otros juegos, está sometido a modas. Hay una razón de gran relevancia que explica que este juego sea sustantivamente ocasional. Otros mensajes de la tradición oral no se gastan tanto, pero este, efectivamente, pierde completamente tensión e interés si todos los que juegan conocen de antemano las soluciones. Propuesta una adivinanza y otorgada la solución, se gasta y se anula la continuidad del juego, depende pues del número de adivinanzas disponibles y de la amplitud de la red social. Si el número de adivinanzas es reducido, como normalmente lo es y si la red social es limitada — y mucho más aún si es cerrada-, el tiempo dedicado a este juego está destinado a ser necesariamente breve.

\footnotetext{
${ }^{3}$ En algunas áreas determinadas se usan otros como quisicosa o adivinas y en el siglo XVII en Castilla se usaban los de cosicosa, pregunta, perqués. etcétera.

${ }^{4}$ Según A. Redondo tuvo mucho auge en la sociedad española del Siglo de Oro, tanto entre las capas populares como en la Corte (1980: 446).
} 
No es, por otra parte, un juego de temporada, aunque se haya asociado a los entretenimientos del invierno o de los periodos en los que la lluvia o el frío obligan a resguardarse en casa o en los locales públicos de encuentro ${ }^{5}$.

En suma, no solo era un juego de niños, sino también en no pocas ocasiones de adultos como grupos de amigos o de vecinos y, a veces, un juego entre adultos y niños. Y no era y no es un juego demasiado formal. En realidad, se sitúa más entre los entretenimientos intersticiales o aparece mezclado con chistes, cuentecillos y anécdotas, entre otros.

El juego es mucho más dinámico de lo que la imagen de una estructura, por aclaratoria que sea, pueda mostrar. Siempre hay dos y solo dos papeles a desempeñar, aunque intervengan dos o más de dos posibles jugadores. No tienen término específico que los denomine, así que se distinguen por la acción y por la parte del discurso dialogado que han de componer. Enunciar la adivinanza es la acción básica atribuida al primer papel, mientras que «adivinar» o «acertar» es la acción básica del segundo papel y que debe realizar el que acepta la adivinanza.

Para empezar, no siempre se está dispuesto a jugar. Por una parte, quien sabe una adivinanza, la arriesga. Si la audiencia la conoce, su propuesta no solo se pierde inútilmente, sino que su posición queda debilitada («Queda corrido», decían los clásicos). Por otra parte, y pese a su insistencia puede no encontrar quien la acepte. Aceptarla es también un riesgo, doble riesgo, tal vez. Si no se logra dar la respuesta adecuada, se compromete la posición social, se corre el riesgo de ser públicamente denigrado y sobre todo se está en dependencia indefinida de «quien la sabe» hasta que este le dé la respuesta. Asimismo, la seriedad del juego puede tornarse inopinadamente en burla y lo que parecía ser un desafío, en realidad resulta ser una trampa.

Parece haber una evaluación de las adivinanzas propuestas en relación con la audiencia que pudiera recibirlas. Además de otras apreciaciones de la conveniencia del contenido de determinados mensajes, parece existir una percepción del grado de dificultad relativa. De forma que determinadas adivinanzas se consideran apropiadas para niños pequeños, como las adivinanzas que incorporan la figura del calambur, como «Oro parece, plata no es, el que no lo acertare» $\mathrm{o}$ «Ave tengo por nombre, llana de condición», pero no para tan avezados jugadores, como suelen ser los de 10 a 12 años, que considerarían ofensivos enunciados tan simples. Las reglas del desafío exigen contrincantes apropiados y siendo demostraciones de saber, el planteamiento de la adivinanza debe ser un acto meditado. Entre adultos no hay evaluaciones de dificultad, pese a que suele ser tópico de los cuentos de adivinanzas. El saber se demuestra ya planteándola, pero, en teoría, ninguna se conoce salvo que se haya sido receptor de ella en un episodio anterior. Ciertamente los niños reciben «nuevas» adivinanzas de los mayores y, cuando las transmiten a sus respectivos grupos de iguales, es posible que hayan tenido que sufrir antes la dependencia de quien sabía la solución y tuvieron que esperar de él la respuesta. Si bien la ocasión de plantearla ante otra audiencia distinta puede servir para compensar las humillaciones antes sufridas.

Si se piensa en una forma canónica de la adivinanza como juego, tendría que ser algo más que la forma canónica de la adivinanza como discurso. Tal vez, al menos con las siguientes fases:

\footnotetext{
${ }^{5}$ También A. Redondo y otros han ligado la adivinanza al Carnaval, y tiene sentido tal asociación, pero cabe pensar que durante el Carnaval fueran más empleadas adivinanzas de cierto tono y contenido (1980: 454).
} 
1) Planteamiento: en un grupo social alguien adopta uno de los papeles del juego; deja explícito el código de reglas que implica advirtiendo su intención de exponer un enunciado que ha de ser tomado como «adivinanza»; otro u otros del grupo aceptan el juego y adoptan el papel cuyo objetivo es intentar resolverla; y se emite el enunciado. En esta primera fase el protagonismo del juego lo tiene quien propone la adivinanza.

2) Análisis: el protagonismo del juego lo ejerce ahora el o los que la han aceptado. El enunciado es recibido con atención, es verificado en cuanto a su integridad y ratificado en cuanto a la pertinencia de los elementos presentes en él y luego sometido a análisis, según procedimientos habituales, no necesariamente verbalizados, ateniéndose a episodios anteriores en los que se ha participado como audiencia pasiva al menos o como audiencia participante. Se ensayan respuestas posibles y se solicita del que ha propuesto la adivinanza un veredicto de corrección. Si ninguna es correcta, se siguen las siguientes fases.

3) Negociación: se solicitan «pistas» adicionales relativas al enunciado o al grado de aproximación de las respuestas.

4a) Resolución: el o los que aceptaron la adivinanza dan una respuesta que es reconocida como solución, cuando el que la propuso admite su corrección.

4b) Resolución: el o los que aceptaron la adivinanza declaran explícitamente su incapacidad, mediante la fórmula «darse por vencidos»; quien la propuso otorga, entonces, la solución y la justifica.

5) Premio o sanción: no siempre tiene lugar, pero en ocasiones se marca con intención, sobre todo si la adivinanza estaba cargada de intención o si fue presentada como un desafío. Tras esta última fase, en su doble posibilidad, queda la satisfacción, la mirada ufana y las muestras de suficiencia por parte del que la logró acertar; o bien la risa y la burla, la sanción que contiene una calificación — «tonto» o «burro»— por parte de quien la propuso y dirigidas a quien fue incapaz de dar la solución.

Pero un juego es un proceso y, más que una estructura, debería ser descrito como un itinerario que progresa si y solo si se asumen alternativas de continuidad. Efectivamente el proceso sucede en fases, pero las fases tienen lugar en la medida en que la negociación supere la posibilidad permanente del conflicto. El rechazo es una posible reacción primera, pero cabe una negociación que ha conducir a aceptar el juego y distribuir los papeles. Una vez expuesto el enunciado adivinatorio, dada su naturaleza, cabe otra vez la negociación con el fin de ratificarlo. También puede acabar súbitamente el juego, si la adivinanza era conocida y se ha dado la solución al instante. Si no es así, y las respuestas primeras no son correctas, cabe de nuevo la negociación respecto a nuevas pistas y el conflicto si estas se niegan. Si se consiguen algunas, pueden darse otras respuestas y si no son correctas, negociar sobre nuevas pistas o sobre una ampliación del plazo, etc.

Parece que el proceso tiende a configurarse en relación a dos modelos en cierto modo opuestos. En ambos el valor en juego es el saber. El supuesto es que las posiciones sociales de partida son desiguales. De los dos papeles del juego, el que propone la adivinanza y, por tanto, tiene la solución, se percibe en una posición superior (en cuanto al saber) respecto a la audiencia supuestamente situada en posición inferior (o al menos no definida). No es casual que los contendientes en los cuentos de adivinanzas sean, por un lado, los reyes y sabios y, por el otro, jóvenes desheredados que ganando el desafío consiguen con ello la igualdad en la posición social como premio y como correspondencia a la equiparación de saber. 
En los cuentos de adivinanzas existen pues dos modelos. El primero de ellos es la confrontación, el desafío, y el destino para quien no puede resolverlas es la muerte ${ }^{6}$. El segundo de los modelos se aproxima, por el contrario, al mantenimiento de las posiciones relativas supuestas y reproduce una transmisión unidireccional (una exhibición del saber). La audiencia es pasiva, ya que recibe el enunciado adivinatorio, se confirma su incapacidad y acaba reforzándose su subordinación al recibir también la solución. La ficción pintada por los cuentos refleja el hecho de que las posiciones de partida no son iguales y afirma el valor del saber y la eficacia social que conlleva.

Es evidente que el juego en buena medida desdramatiza las situaciones, pero los dos modelos del proceso persisten. Por un lado, el desafío, que puede concluir reequilibrando las posiciones relativas o acentuando la superioridad e inferioridad de unos o de otros. Acertar no solo es una satisfacción, también logra haber neutralizado una pretensión de superioridad. No acertar es quedar por tonto, por simple y dependiente de otros, si se deseara seguir jugando. Por otro lado, la exhibición, incluso cuando la solución se da casi a continuación del enunciado adivinatorio (como si se estuviese haciendo un relato, como si no fuese un discurso dialogado), pretende dejar sin opción la intervención de otros. La exhibición sucede gracias a que, de la misma manera que prevé el propio enunciado que incorpora una forma interrogativa, el enunciante pretende impedir que otros lleguen a completarlo. Pretende protagonizar en exclusiva el juego y el saber. Y casi todos los modos de jugar se sitúan entre estos dos modelos.

\section{DE LA ESTRUCTURA DE LAS ADIVINANZAS A LOS PROCEDIMIENTOS DE LA CRIPTIFICACIÓN Y DEL DESVELAMIENTO}

Trascendente o intrascendente, como desafío o como exhibición, el juego no tendría sentido si no se fundamentara en una transformación de la realidad. La dinámica del juego indica que estrictamente dicha transformación consiste en haberla ocultado en parte, mientras que el procedimiento del adivinar consiste aparentemente en desvelarla. Y las «pistas» ya indicadas en el enunciado y las aportadas a lo largo del juego son desvelamientos parciales, que terminan por realizar definitivamente la transformación con la solución. El material y los mecanismos de la ocultación y del desvelamiento los proporciona a nivel múltiple el lenguaje. Esta faceta del proceso en las adivinanzas fue muy bien percibida por Cervantes en el libro sexto (y último) de La Galatea:

Es muy escura y es clara,

tiene mil contrariedades,

ocúltanos las verdades

y al cabo, nos las declara.

(2004, ed. Real Academia)

Entre las sugerentes teorías sobre la estructura de las adivinanzas, E. Köngas Maranda (1971) imagina que toda adivinanza establece una relación entre un significante (término dado) y un significado (la respuesta). Esta relación se desarrolla por medio de cinco elementos: el significante, una premisa constante (válida tanto para el significante como para el significado), una variable escondida (que caracteriza al significado), otra variable declarada (que también caracteriza al significado, aunque esté atribuida al significante) y el significado (término no dado). No obstante, hay que estar de acuerdo

\footnotetext{
${ }^{6}$ Seguramente por el riesgo de subversión o por la osadía del desafío, como puede leerse en A. M. Espinosa (1952), «Cuentos populares españoles», n. ${ }^{\circ} 1$ al 30.
} 
con Todorov en que no se puede suponer que la relación establecida se refiere solo a un término dado y otro no dado, sino entre el enunciado adivinatorio como un todo y la solución, entre otras razones, porque muchas adivinanzas carecen de término dado y porque la solución no tiene por qué ser otro término (1978: 253).

Efectivamente Köngas Maranda, a diferencia de Todorov, recoge muy acertadamente que el enunciado contiene elementos que ocultan y elementos que desvelan la solución. Eso es lo que hace posible el juego, que en realidad es una mostración diferencial de saber, a la vez un desafío y una prueba. Los enunciados adivinatorios reflejan la doble posición de los papeles del juego. En ellos se debe dar muestras de conocimiento y hacerlo de modo que atraigan al juego a quienes no lo tienen, captando su atención y focalizando su mente. Es así que no se trata de una transmisión gratuita del conocimiento, sino de una adquisición por confrontación, con la posibilidad permanente tanto de la humillación como del engaño.

Los enunciados adivinatorios pueden estar llenos de trampas, por lo que estimulan al razonamiento, aunque lo inducen a seguir por caminos erróneos al hacer parecer evidente lo que no es o insinúan enorme misterio en lo que en realidad es algo común. Los procedimientos para hacerlo son los que se analizan a continuación ${ }^{7}$.

Se advirtió anteriormente que la consideración de las adivinanzas como definiciones obligaba a un contraste espurio de aquellas con las definiciones de diccionario y se presume que las adivinanzas se apartan de estas en cuanto a la claridad. Aunque, paradójicamente, una definición de diccionario puede llegar a ser enormemente más enigmática que una adivinanza, como es el caso del uso de la terminología científica para describir las características y propiedades de los minerales, los vegetales o los animales que los hacen prácticamente irreconocibles para los no versados. Pero, en esencia, cualquier lenguaje funciona para otro como un enigma. Y la escritura puede ser un enigma para quienes no saben leer. Las adivinanzas no se distinguen solo de las definiciones de diccionario porque no están institucionalizadas (han sido elaboradas por el lenguaje común, según Todorov [1978: 251]), sino porque lo están de otro modo, no solo distinto de cómo se hace en los diccionarios, sino también de otro modo que el lenguaje común. «Jugar a las adivinanzas» es un código cultural y, evidentemente, una institucionalización.

El instrumento del juego es el lenguaje y sus recursos. Las reglas del juego incluyen entre otras cosas la idea de que los enunciados adivinatorios y las soluciones se suceden y se corresponden (siguen el orden de la combinación y el orden de la selección, que diría Jakobson [1963]). La secuencia y la correspondencia implican al instrumento del juego (el lenguaje) y a los jugadores. La regla de secuencia obliga a los jugadores a intervenir a su tiempo, aportando cada uno un fragmento distinto de un único y mismo discurso, cuya garantía y, a la vez, fuente de incertidumbre es la correspondencia entre ambos fragmentos. La correspondencia es supuesta, pero no explícita. Está incorporada, pero no es evidente. Las categorías claridad-oscuridad que mencionaba Cervantes son reveladoras de esa doble cara del juego.

Si esas dos categorías se tomaran como un parámetro susceptible de ser aplicado a los enunciados adivinatorios, los más claros se aproximarían al grado cero de la adivinanza, como sucede en el siguiente caso:

\footnotetext{
${ }^{7}$ Se podría igualmente decir que se trata de elementos que desvían de y elementos que señalan a la solución. Si así fuera, los enunciados aparecerían como itinerarios que conducen a una meta, pero los itinerarios de las adivinanzas tienen tramos sin salida y tramos expeditos: son laberintos. He aquí entonces dos analogías que describen la razón, la razón «vestidora» y la razón «itinerante».
} 


\begin{abstract}
Este banco está ocupado
por un padre y por un hijo.

El padre se llama Juan

y el hijo ya te lo he dicho.

Esteban.
\end{abstract}

Además, aunque no se deduce necesariamente del enunciado, una adivinanza muy conocida tiene funcionalmente la misma condición de claridad que estos dos ejemplos aducidos. El grado cero de la adivinanza tiene pues tres relieves: la sinonimia, la homonimia y el conocimiento común. Los ejemplos que se refieren al grado cero de la adivinanza son descripciones literales que emplean el sentido recto de las palabras, pero las soluciones responden a dos funciones muy diferenciadas de la comunicación. La primera de ellas explota la función referencial y la segunda es un enunciado metalingüístico. Se trata así de un enunciado declarativo que contiene la solución disimulada por medio de una figura llamada «calambur». Además, incluye de forma explícita el código de desciframiento con la frase «ya te lo he dicho».

La claridad no es necesariamente la cualidad definitiva de ese grado cero, ya que es solo una valoración relativa. Tal vez no haya un grado cero absoluto de la adivinanza, no solo porque todo lenguaje es arbitrario, ni debido a que el discurso se construye sobre la ambigüedad y contando con la polisemia de los términos, tampoco a causa de que se forma con toda una serie de figuras de pensamiento y de dicción que obligan a permanentes interpretaciones, sino porque se trata de un juego que se mueve impredeciblemente entre diversos códigos.

Además, por encima de ese grado cero se producen las transformaciones, actúan los procedimientos de la criptificación. No obstante, no podrían concebirse como situados en un único eje. Imaginariamente remiten todos a un grado cero, aunque no están vinculados con él paramétricamente. Se trata de direcciones divergentes de transformación, de las que solo algunas admiten progresión en intensidad. Se podría decir que la criptificación es el resultado de la exploración de distintas, pero predecibles, «anomalías» o variaciones del orden de la combinación y el orden de la selección.

El conjunto de tropos y figuras que reiteradamente se han señalado como integrantes de la estructura de las adivinanzas muestran esas variaciones. Especialmente se han destacado, por un lado, las paradojas y, por otro, las alegorías. Las primeras, efectivamente, podrían ser contempladas como elaboraciones antinómicas (variaciones sobre la sinonimia) y las segundas como elaboraciones del sentido figurado (variaciones sobre la literalidad, sobre el sentido recto). Pero no son los únicos procedimientos de la criptificación.

Uno de los más básicos solo se percibe cuando se analizan distintos enunciados adivinatorios que son versiones distintas o variantes unos de otros y cuando se atiende a la etnografía del juego. Las versiones se diferencian claramente en el número de elementos de identificación otorgados. Algunos enunciados parecen tan escuetos que se dirían, antes que otra cosa, formados por elipsis. No obstante, todas las versiones, aun cuando sean unas más desarrolladas que otras, contienen solo un número limitado de elementos de identificación. El juego como proceso, ya se dijo anteriormente, suele pasar por una fase de negociación en la cual se trata de obtener más «pistas», pero el número de «pistas» concedidas no puede ser indefinido. Desde esta perspectiva la adivinanza más enigmática se aproximaría a aquellos enunciados que osan formular la vieja pregunta con 
la que en tiempos se iniciaba el juego: «¿Qué es cosa y cosa?». Un juego infantil actual, el «veo, veo», lo descubre de forma gráfica:

Jugador 1: Veo, veo.

Jugador 2: ¿Qué ves?

J1: Una cosita

J2: ¿Con qué letrita?

J1: Empieza con la letrita...

A partir de aquí y hasta la serie de respuestas fallidas le sigue un número progresivo de «pistas», es decir, de letras que componen la palabra que se refiere a la «cosita», hasta que la solución se hace evidente. De este modo la aproximación al grado cero de la adivinanza se logra al proporcionar un número tan amplio de elementos de identificación que convierten el enigma en evidencia. El procedimiento de la criptificación consiste por el contrario en reducirlos. El enigma por excelencia es lo que no tiene nombre y, por el contrario, no hay misterio ninguno en aquello que está en boca de todos. Muchos enunciados son construcciones metonímicas (una serie de elementos de identificación complementarios), pero una serie limitada. La elipsis es un supuesto, aunque los elementos proporcionados se consideran suficientes:

Pila sobre pila, sobre pila, oliva, sobre oliva, trapo, atínamelo, guapo. El candil.

Casquete, casquete, casquete de paño fino, no lo acertarás en un año, ni en dos si no te lo digo. La cebolla.

Por otro lado, cuando se comparan diferentes versiones, generalmente difundidas en distintas áreas, se percibe que los elementos de identificación proporcionados son una selección entre un conjunto posible de ellos, por ejemplo:

Tamaño como una taza

y tiene la cabellera en la panza.

La cebolla.

En el campo me crié, metida entre verdes lazos, aquel que llora por mí, me está partiendo en pedazos.

La cebolla.

Entre sábanas de Holanda y colchones de marfil, tuvo la infanta un infante más verde que el perejil. La cebolla. 
Estos dos últimos enunciados, aunque alegóricos, son funcionalmente similares a los anteriores en que contienen elementos de identificación y así suelen ser tomados. Cualquiera de ellos es una selección, si se quiere, significativa, pero en todo caso parcial. Se trata de un ocultamiento intencionado, un procedimiento de criptificación básico que remite, por defecto, a conjuntos generales e imprecisos. El uso de términos genéricos tiene la misma función. Las descripciones realizadas con ellos son tan imprecisas que exigen informaciones complementarias. Los rasgos descriptivos básicos, por ejemplo, color, altura, forma, volumen, materia, entre otros, son demasiado abstractos y, del mismo modo, requieren concreción. Las relaciones propuestas pueden aparecer como meras y vagas asociaciones $\mathrm{y}$, por lo mismo, necesitan elementos de enlace. Todos estos procedimientos de la criptificación se basan, sin embargo, en la sinécdoque, una figura que oculta por englobamiento. Entonces, la concesión de «pistas» en el proceso de aproximación a la solución puede ser descrita como un proceso de disgregación y desmenuzamiento o como un descenso de lo general a lo particular, de lo abstracto a lo concreto.

Asimismo, en los enunciados adivinatorios aparecen varios mecanismos de reducción a lo particular y concreto. A veces, algunos enunciados contienen reductores, como los términos de referencia de una comparación. Tal es el caso de:

\section{Redondo como una cazuela, tiene alas y no vuela. \\ El sombrero. \\ Largo, largo como una soga y tiene dientes como una loba. La zarza. \\ Largo, largo como un camino y cabe en un pucherino. \\ El hilo.}

En estas adivinanzas, los términos de referencia son reductores porque no solo responden a las categorías descriptivas, sino que añaden otros rasgos útiles para la identificación.

Como Georges y Dundes advirtieron (recordando a Aristóteles), en los enunciados adivinatorios se utilizan diversas formas de oposición: privativas, causales y antitéticas (1963: 113). Sin embargo, como se verá a continuación, el espectro es más amplio. Aunque no pueden considerarse, como pretende Todorov, la trama fundamental de la articulación de las adivinanzas, constituyen uno de los procedimientos más brillantes de la criptificación (1996: 255 y ss.). Las formas más impactantes, las paradojas, hacen aparecer el juego como un «espacio» cualitativo cerrado, sin salida; mientras que la metáfora, como mostró Fernández, es movimiento en el espacio cualitativo (1974: 122). La adivinanza representa un espacio definido por una dimensión que se cierra presentando los polos extremos. La solución es entonces una liberación. Es así que las paradojas se ajustan de esta manera muy apropiadamente a la relación de dependencia establecida entre los papeles del juego de las adivinanzas. Y el saber aparece, por un lado, como la capacidad para construir espacios cualitativos cerrados que atrapan las mentes de otros y, por otro lado, como una habilidad para librarse de ellos. En realidad, se trata de falsas paradojas: ataduras confeccionadas con materiales lingüísticos, palabras polisémicas, 
códigos que determinan significados a distinto nivel, frases de doble sentido, pero artificiosamente presentadas. La paradoja como procedimiento de la criptificación parece inducir la idea de que el objeto o acción de referencia es imposible, no existe, puesto que la combinación de atributos ofrecidos es inviable; como si los objetos y acciones desaparecieran bajo del artificio lingüístico.

Además, algunas oposiciones no son más que construcciones metonímicas, como las ya mencionadas, solo que están soportadas por categorías de contraste binario: dentrofuera, debajo-encima. Por ejemplo:

Amarillo por dentro y blanco por fuera.

El huevo.

Otras adivinanzas aparentan disociar determinados atributos de sus respectivos sujetos prototípicos:
Tiene cuatro patas
y no es banquete,
husmea
y no es podenco,
hace tinajas
y no es tinajero.
El escarabajo.

También aparentan disociar determinados sujetos de sus respectivos atributos o elementos característicos:

Con muchos remiendos y ninguna puntada.

La gallina.

Un vestido sin costura.

La culebra.

Un convento sin campanas ni torres.

La colmena.

Una tinajilla sin tapa ni tapón.

El huevo.

Unas y otras adivinanzas funcionan como fórmulas de eliminación de respuestas comunes, pero inadecuadas. A veces se vinculan atributos no congruentes. Tal es el siguiente caso:

Tan alta como un castillo

y pesa como un anillo.

La caña.

Largo, largo como un camino

$\mathrm{y}$ cabe en un pucherino.

El ovillo de hilo. 
En algunos enunciados se intensifican las negaciones de atributos hasta el punto de descargar descriptores de un término dado como si se tratara de formar significantes «vacíos», como:

Largas varetas,

ni verdes ni secas,

ni por agua regadas,

ni en tierra sembradas.

Los rayos del sol. funciones:

En otros se presentan en oposición órganos o instrumentos y sus respectivas

Tiene dientes y no come.

El ajo.

No tiene pechos y cría.

El murciélago.

Camina y no tiene pies.

El caracol.

También se asignan funciones a órganos inapropiados en las adivinanzas:

Muchos soldados en fila,

hablando por la barriga.

Los botes de la botica.

O se desligan acciones habitualmente sucesivas u ordenadas en secuencia de causa a efecto:

Anda, anda

y nunca llega a Peñaranda.

El reloj.

Mil damas en un camino, sin polvo ni remolino.

Las hormigas.

Una arquita que se puede abrir, pero no se puede cerrar.

El huevo.

Sube al tren y no paga nada.

La mosca.

Estoy en lo alto, moros veo venir y no puedo huir.

El reloj de la torre. 
En algunos enunciados se ofrece invertida la sucesión generacional:

Antes de que el padre esté hecho, ya está en hijo en el techo.

El fuego y el humo.

En otros, se subvierten las relaciones intergeneracionales:

¿Cuál es el hijo cruel que a su madre despedaza, y su madre con la misma traza lo va despellejando a él?

El arado y la tierra.

En determinados enunciados la subversión aparentemente afecta al orden social, incluidas las posiciones relativas del Creador y las criaturas:

Un rey pidió a su criado

lo que en el mundo no había;

el criado se lo dio

y él tampoco lo tenía.

El bautismo de Jesucristo por San Juan Bautista.

Vio un pastor en su cabaña,

lo que no vio el rey de España,

ni el Pontífice en su silla,

ni Dios, sin ser maravilla.

Otro pastor.

Más alta que Dios subí y en el cielo y en la tierra nadie se encuentra sin mí.

La cruz.

Finalmente, algunas oposiciones son aparentes contradicciones estrictas que desafían la lógica común. Uno de esos enunciados es al que, en la Antigüedad, se atribuyó la muerte de Homero, profundamente afligido por no haber podido llegar a su solución, quien estando en la playa contemplando el mar, vio venir a unos pescadores con la barca vacía. Les preguntó qué había sucedido y le respondieron con un enigma: «Lo que cogimos, lo tiramos; lo que no cogimos, lo traemos». Un enunciado semejante aparece en algunas colecciones actuales: «Si las tienes, las buscas; si no las tienes, ni las buscas ni las quieres». Los pescadores en el legendario relato sobre la muerte de Homero se referían a los piojos. El enunciado de las colecciones actuales tiene como solución a las pulgas. Otros enunciados adivinatorios dan contornos contradictorios a «cosas» (un término que induce entidad), cuya descripción propia es la carencia. Tal es el caso de las siguientes adivinanzas:

¿Qué cosa es, que cuánto más grande,

menos se ve?

La oscuridad. 
¿Qué cosa es, que cuánto más le quitas, más grande es?

El hoyo.

Y otros aún parecen ser rotundas proposiciones conceptual o lingüísticamente contradictorias y quiasmos:

¿Qué es algo y nada a la vez?

El pez.

Cuanto más cerca, más lejos, cuanto más lejos, más cerca.

La cerca.

En contraste con la amenazante subversión o con el pretendido desafío a toda racionalidad de algunos enunciados, las soluciones muchas veces son decepcionantemente intranscendentes. Y, posiblemente, el juego de las adivinanzas pueda ser mejor comprendido bajo el signo del contraste entre estas dos caras. Por un lado, permite formular con osadía proposiciones aparentemente transgresoras de todo tipo de orden: desafiantes al sentido común y a la racionalidad e incluso exploratorias del absurdo. Por otro lado, con las soluciones se confirma que el juego no se ha elevado más allá de la cotidianidad, que todo era un mero artificio construido con y sobre las palabras.

Los procedimientos de la criptificación que se revelan a través de todas las formas de oposición antes reseñadas consisten fundamentalmente en transformar la realidad rompiendo su orden, subvirtiéndola. Introducen quiebras o rupturas del orden de las cosas o del orden social o establecen reordenaciones no solo sorprendentes sino improbables.

Unas deshacen asociaciones tenidas como necesarias, mientras que otras descubren asociaciones entre elementos contrarios. Unas desbaratan secuencias obligadas, mientras que otras encadenan acciones dispares. Unas rellenan ámbitos con elementos heterogéneos, mientras que otras vacían de contenidos términos perfectamente reconocibles. Unas inducen vías de razonamiento que conducen a conclusiones inadecuadas, mientras que otras, incluso mencionando posibles respuestas, perversamente obstruyen todo tipo de senda que conduzca a una solución. En sus formas más radicales las oposiciones pretenden forjar un cierre a los espacios cualitativos de forma que no parezca posible encontrar una salida. Pudiera tomarse como ejemplar un subtipo de adivinanzas que podrían llamarse «dilemas existenciales» y que describen precisamente situaciones sin aparente escapatoria posible. Por ejemplo:

Estás encerrado en una habitación con cuatro puertas. Detrás de una de ellas hay una manada de toros bravos, detrás de otra hay cuatro leones muertos de hambre, detrás de otra hay un foso muy hondo y detrás de la última hay tres cocodrilos feroces. ¿Por cuál de ellas escaparías?

Por donde están los leones muertos de hambre, porque están muertos.

En contraste con las oposiciones, las metáforas proporcionan por el contario desplazamientos, vías de salida y a la vez son, por antonomasia, procedimientos de transformación. Fue Aristóteles quien percibió la estrecha imbricación de los enigmas y las metáforas: 
No hay que traer las metáforas de lejos, sino de cosas que son del mismo género y especie, al dar nombre a lo que no tiene, y resulta claro, en cuanto se dice que corresponde al mismo género, como en el famoso enigma: «Vi a un hombre que con fuego bronce sobre un hombre pegaba», porque la operación no tiene nombre, pero ambas cosas son aplicación de algo, y así se dijo pegar por la aplicación de la ventosa. En general, de enigmas bien construidos se pueden sacar metáforas adecuadas, porque las metáforas implican el enigma, de donde es evidente que está bien traída (Retórica III, 1405 a 34).

Y más adelante: «los enigmas bien hechos son por lo mismo agradables, porque son una enseñanza y se dicen como metáfora» (Retórica III, 1412 a 23). Esta apreciación de Aristóteles no ha sido apenas tenida en cuenta en los estudios sobre las adivinanzas desde el folklore, aunque sí ha sido advertida en el redescubrimiento de la metáfora por parte de antropólogos cognitivistas (David Sapir, entre otros).

Explorando metáforas en las adivinanzas cabe reseñar de entrada un doble modo de imbricación. Por un lado, como en el ejemplo aportado por Aristóteles, en enunciados adivinatorios se pueden hallar analogías simples; pero, por otro lado, destacan aún más numerosas construcciones cuya artificiosidad les sitúa en el nivel de la alegoría. Un nivel tan habitual y esperable que el impacto analógico se reduce hasta hacerse tenue y predomina el carácter de mera fórmula, hasta el punto de operar más como mecanismo codificador de enunciado adivinatorio. He aquí algunas de las fórmulas más empleadas:

- «Una señora muy aseñorada» y variantes como «Una señora alta y delgada»o «Una dama compuesta» remiten a soluciones tales como gallina, cebolla, berenjena, botella, luna, sombra, lengua, entre otras. Todas efectivamente nombres femeninos de «cosas».

- «Una vieja titiritaña»y variantes como «Una vieja tontilloca»o «Una vieja seca y meca» $\mathrm{y}$ «Una vieja larga y seca» remiten a soluciones tales como hormiga, campana, piña, vela, neblina, muerte, etcétera. Todas también nombres femeninos de «cosas».

- «Verde fue mi nacimiento» o «Blanco fue mi nacimiento» es el inicio de enunciados que se dirían «biográficos», en los que se describen las mutaciones de color a lo largo de un ciclo vital. Remiten a soluciones como hormiga, lagarto, cóndor, flor de jara, algodón, zarzamora, café, tabaco, arroz, mora, trigo, aceituna, lino, corona de espinas, baraja, entre otros. Es decir, algunos animales y sobre todo un buen número de vegetales y especialmente aquellos que son objeto de elaboración y transformación para el consumo humano.

- «En el campo fui nacido» o «En el monte fui nacido» con variantes como «En el campo/en el monte me crié» son inicios de enunciados no tanto biográficos cuanto de «identificación», asumiendo como pauta la referencia al lugar de origen y crianza. Remiten a soluciones como conejo, oveja, lagarto, ruiseñor, amapola, cebolla, pimiento, tabaco, mesa, cruz, leña, etcétera. Todos ellos animales o vegetales o de procedencia vegetal.

Lo que resalta más de estas fórmulas es el uso habitual de la personificación y la prosopopeya en las adivinanzas, como ya había indicado Pérez Vidal en un intento de análisis sobre la estructura de las «adivinas» canarias (1986). Las adivinanzas casi nunca versan sobre papeles sociales de los seres humanos, sino sobre «cosas» y la transformación alegórica de estas se logra por desplazamiento hacia un espacio cualitativo definido como «humano». Como lenguaje de la criptificación resulta sorprendente, pues lejos de ocultar las «cosas» en figuraciones extrañas, parecen haberse aproximado a los rasgos de reconocimiento humanos. Por medio de la personificación 
objetiva, muchas «cosas» son transformadas en hijos, padres, hermanos, viejas, señoritas, frailes, caballeros, entre otros, o les son atribuidos nombres propios como Doña Úrsula, Ana, Martín, María, etcétera. Los desplazamientos en realidad se producen, también, del mundo de las cosas inertes al mundo animal y de ambos al mundo humano, pero casi nunca al revés. De forma que todas estas construcciones alegóricas dotan de animación al universo que es objeto de adivinación. Cada objeto convertido por metáfora en sujeto es descrito con cualidades, atributos, acciones y pasiones. Y así la noche es:

Una vaquita negra
que cayó al mar
y los hombres
no la pudieron salvar.

o

Una mujer triste, muy secreta y reposada de cuerpo y alma privada, que de negro siempre viste.

La nieve es:

Las tocas de Doña Leonor que los montes cubren y los ríos no.

O

La madre engendrada de la hija que parió, que sin padre se formó, $y$ en otro ser transformada al antiguo se volvió.

\section{La luna es:}

Una yegüita muy blanca salta el cerro y la barranca y nunca jamás se manca.

Y las ranas son:

Trescientos caballeros, bajo el puente de Cameros, que han perdido sus caballos y cantan más que los gallos.

Y la granada es:

Un convento

con muchas monjitas dentro, 
con un velo tan delgado

que ni es de lana ni es hilado.

O bien cada «cosa» convertida por metáfora en sujeto absorbiendo el enunciado adivinatorio se apropia del pronombre personal, usurpa el «yo» antropomorfo y se describe a sí misma dirigiéndose efectivamente a los humanos. Y así el romero dice de sí mismo:

Mi nombre es de peregrino

y tengo virtud notable,

jamás se supo que hable

ni que anduviese camino

y mi olor es agradable.

El reloj por su parte afirma:

Soy caballero aseñorado,

tengo doce damas para mi regalo,

todas van en coche y gastan zapatos,

todas usan medias, pero no zapatos.

Y el huevo declara su ascendencia diciendo:

Mi madre es tartamuda

y mi padre es cantor,

tengo el hábito blanco

y amarillo el corazón.

Todos estos enunciados reproducen los mismos caracteres de la personificación objetiva, pero el «yo» usurpado sitúa a estas «cosas» ante los jugadores del juego de las adivinanzas. Los enunciados adivinatorios en primera persona realizan una increíble pirueta que traslada las «cosas» al medio del mundo humano, preguntando, interpelando, poniendo asombro, haciendo guiños sobre su identidad. Todavía en la personificación objetiva se sobreentiende que el «yo» corresponde a quien emite el enunciado adivinatorio, pero en los enunciados adivinatorios de personificación subjetiva se ha producido una disociación entre el «yo» de la interacción en el juego (el «yo» de la enunciación) y el «yo» hablante de los enunciados. Todo ocurre como si la «cosa», que es objeto de la adivinanza, tomara la boca y las palabras del que profiere el enunciado y se sirviera de él (mero transmisor) para dirigirse a la audiencia. Pareciera que estos enunciados hacen desaparecer al propio locutor y obligan a quien aceptó el juego a enfrentarse con un pronombre incoado, un «yo» no evidente como su interlocutor, que se sabe que no es este, sino otro (inevitablemente antropomorfo) expuesto en metáfora y, por tanto, enigmático.

Precisamente ocurre que desaparece el «yo» del locutor. Mientras que, por el contrario, los términos que designan a la audiencia — el pronombre de segunda persona (el «tu» del «adivina adivinanza») y los vocativos y calificativos («estudiante de letra menuda», «entendido», «prudente», «tonto», «bobo», «burro», entre otros) - casi siempre son alusivos a un status del saber, con los cuales se le incorpora a los enunciados adivinatorios, le sitúan inequívocamente en escena presente, atentos, atados y calificados por su actuación e implicado en el juego hasta que no proporcionen la solución. 
Pese al ilustrado análisis de M. Bassols (1991), el contexto del juego y las relaciones sociales establecidas entre los jugadores no desaparece, salvo que se considere que las adivinanzas son solo textos. El locutor no desaparece en el contexto del juego, pero una buena adivinanza consigue una focalización sobre la «cosa» y, en realidad, sobre el discurso mismo por parte de quien la acepta. Esa focalización está presentada en forma de proyección y la personificación no es otra cosa sino una proyección. Se trata, así de una extraña relación de comunicación establecida por enigmáticas «cosas» que se dirigen a la audiencia por medio de un pronombre incoado, un «yo» desconocido, pidiendo ser identificadas. El esquema reproduce las escenas carnavalescas de máscaras dirigiéndose unas a otras la pregunta y el desafío: «Adivina quién soy yo». En las adivinanzas son las «cosas» enmascaradas con la metáfora de la personificación las que preguntan por su identidad, por ejemplo:

En medio del cielo estoy, sin ser lucero ni estrella, sin ser sol ni luna bella, ¿a que no sabes quién soy?

Además, en los enunciados no siempre desaparece el «yo» del locutor, quien pide una respuesta a la audiencia («adivina»: «dime», «aciértamelo», etcétera), el que declara el código de desciframiento ( «Ya te lo he dicho»), el que indica que tiene la respuesta («[...] como yo no te lo diga, no lo aciertas en un año»), entre otros. Pero en determinadas fórmulas aparece como actor:

Fui al monte, encontré un timón, cortarle pude, rajarle no.

Un pelo.

Fui al campo y corté un palo, que no tenía un geme de largo, hice dos mesas, dos artesas y un canastito para coger cerezas.

La bellota.

Fui al monte, corté un palito.

Vine a mi casa y a bailar se ha dicho.

La escoba.

Iba yo por un camino y me encontré un vestido, ni cortado ni cosido.

La piel de la culebra.

De manera que este «yo» de tales pequeños relatos es genérico, potencial, pues no se trata de discursos elaborados por el jugador, sino de discursos que reproduce. Sin 
embargo, contribuye a generar y a mantener una ambigüedad básica incrustada en los enunciados adivinatorios, que implica la posibilidad permanente de desplazamientos del sujeto al objeto y de un código a otro. En este «yo» genérico, que se refiere propiamente al papel desempeñado en el juego, confluyen tanto el jugador que propone la adivinanza como la «cosa» que se describe en ella. Está, así, en predisposición a ser manipulado mediante la metáfora. Probablemente la personificación fue un «estilo» introducido con éxito en los enunciados adivinatorios, que enlaza con la tradición fabulística de difusión bajomedieval — de ello es muestra el Libro de Apolonio, según J. Pérez Vidal (1953)—; no obstante, constituye una de las formaciones metafóricas más representativas del procedimiento de criptificación en las adivinanzas.

La metáfora deviene en alegoría implicando, a la vez, distintos elementos. A diferencia de la paradoja, la metáfora es expansiva, explora en el espacio cualitativo en una serie de direcciones determinadas. Se trata de transformaciones canalizadas de la realidad y, en cierto modo, predecibles. Los enunciados adivinatorios muestran estas direcciones y ofrecen ejercicios de reconocimiento. Como ilustración pueden servir las elaboraciones metafóricas de la «lengua»:

1. Tema 1: Mojada.

1.1. Lengua-boca-una mujer en casa (una mujer en coche). Como en:

Una señora, muy señoreada, no sale de casa y siempre está mojada.

Una adivinanza muy difundida. O bien, otra más moderna, pero muy difundida:

Una señorita, muy señoreada; siempre va en coche y siempre va mojada.

1.2. Lengua-boca-una tabla en casa, como la adivinanza poco difundida, que aparece en colecciones asturianas:

En mi casa tengo tengo una tablita, bien arregladita; llueva o no llueva, siempre mojadita.

1.3. Lengua-boca-una pava en el cielo. Por ejemplo, la adivinanza, también, poco difundida de la colección argentina:

En medio del cielo hay una pava echada, llueva o no llueva, siempre está mojada.

1.4. Lengua-dientes-boca un jardinero en un jardín de flores:

Un jardín de flores blancas 
y un jardinero encarnado; nunca llueve, nunca nieva, pero siempre está mojado.

1.5. Lengua-dientes-una flor entre murallas:

Entre muralla y muralla hay una flor colorada, llueva o no llueva siempre está mojada.

2. Tema 2. Colorada

2.1. Lengua-dientes-un prado entre vallas:

Entre vallado y vallado hay un prado colorado.

2.2. Lengua-dientes-boca-una vaca entre otras en un corral:

Un corral de vacas blancas

y en medio la colará;

dime, ¿qué cosa será?

3. Tema 3. Sonora.

3.1. Lengua-boca-Doña Úrsula en su cuarto:

Doña Úrsula de Mendiola,

está en su cuarto,

triste y sola,

la cátala,

la mírala,

la escúchala.

Esta adivinanza incorpora un elemento deíctico «la» que conlleva un refuerzo sonoro. No solo aparece en colecciones andaluzas desde el siglo XIX, sino también en Canarias, Méjico, Chile y Perú.

4. Tema 4. Habladora.

4.1. Lengua-dientes-boca-una vieja moviéndose en una estancia:

Treinta y dos sillas blancas

en un rojo comedor.

Una vieja parlanchina

se movía sin temor.

5. Tema 5: Habladora y Presa.

5.1. Lengua-dientes-boca-una mujer custodiada por soldados en una estancia:

Una estancia abovedada

donde el eco se recrea;

un batallón de soldados 
formado en dos hileras;

no son los más fuertes machos,

que son las más fuertes hembras;

está una mujer entre ellos

por parlanchinota presa.

5.2. Lengua-dientes-boca-una culebra guardada por soldados en una cárcel:

Guardada en estrecha cárcel

por soldados de marfil,

está una roja culebra,

que es la madre del mentir.

Esta adivinanza seguramente ha sido difundida a través de letra impresa. Poco conocida, pero registrada entre escolares.

Una de las direcciones metafóricas toma como término primario «una mujer», pero complicado con otros conforma distintas configuraciones alegóricas. Así la asociación lengua-boca se transforma en «mujer en casa» o «mujer en coche». La asociación lengua-dientes se transforma sin embargo en otros términos como «prado», «flor». La asociación lengua-dientes-boca se transforma en «una vieja moviéndose en un comedor con sillas», «una mujer custodiada por soldados en una estancia», «una culebra guardada por soldados en una cárcel». Otras asociaciones como boca-brazo se transforma en «un pozo y una soga» o labios-nariz-ojos-frente en «dos paredes, dos ventanas, dos fuentes y una montaña» o «una puerta, dos ventanas, dos luceros y una plaza» y la asociación boca-dientes-lengua-nariz-ojos-frente en «un convento, monjas, la priora, dos ventanas, dos espejos, una montaña». Las distintas direcciones metafóricas progresan soportadas en la co-implicación de diferentes términos, moviéndose en el espacio cualitativo al tiempo que incorporan valoraciones y connotaciones diversas, que en este caso traducen concepciones sociales y morales de algunos órganos del cuerpo humano bien asentadas en la cultura tradicional. Por ejemplo, la condición femenina está insistentemente descrita en los refranes como proclive a hablar, del mismo modo que el mucho hablar se hace equivaler proverbialmente a mentir mucho. La contención deseable en el hablar se figura «cerrando la boca» $\mathrm{o}$ «sujetando la lengua». La figura se completa atribuyendo a los dientes ese cierre necesario. La cara y la cabeza son asimiladas a una construcción. La disposición superpuesta de boca, nariz, ojos, entre otros, contribuye a figurar un entorno urbano (de puerta a plaza) o un paisaje campestre (de convento a montaña).

Aparecen aquí algunas de las funciones de la metáfora ya desglosadas por James Fernández (1974). Estos procedimientos de criptificación dan como resultado configuraciones sorprendentes, aunque, ciertamente, no pocas de las transformaciones antes reseñadas están profusamente insinuadas en la lírica popular y hay razones para afirmar que tienen una larga historia. Se trata de metáforas típicas.

Pero en cierto modo no son «construcciones» redondas, figuras perfectas en las que encajan los elementos armónicamente, sino metáforas rotas, quebradas en un punto. En muchos enunciados adivinatorios las direcciones metafóricas progresan mediante la co-implicación de términos sin pretender lograr la transformación completa, en algún sentido por mantener el código de juego bajo el que se rigen. Una vieja adivinanza, que aparece en la colección de refranes de Gonzalo Correas (s. XVII) y también en las colecciones actuales, figura el escribir así: 


\begin{abstract}
Heredad blanca, simiente negra, cinco bueyes a una reja.
\end{abstract}

El propio Correas la glosó: «Es pregunta del papel y tinta, dedos y pluma» (1967: 82). A diferencia de las metáforas simples, las construcciones alegóricas para un buen ajuste con lo representado conllevan alguna posibilidad de quiebra. Leído en la continuidad de la asociación alegórica, «cinco bueyes» es un elemento intencionadamente sorprendente, que debiera llevar en el juego a una comprobación. Quien ha recibido la adivinanza pregunta extrañado si no se trata de un «error». Es característico que la quiebra de la metáfora no desvirtúa el enunciado adivinatorio, sino que precisamente remite directa y literalmente a la «cosa», objeto o acción referida. No es por tanto un «error», sino un «indicio», un vano en la hermética cadena por donde escaparse para enlazar con la realidad transformada. Se trata de un reconocimiento de código con el que reconocer una criptificación. «La señora siempre mojada, aunque siempre va en coche», «la vieja parlanchina que se mueve entre las sillas blancas del rojo comedor», «la roja culebra que es la madre del mentir», entre otras, son todas metáforas rotas, con elementos que funcionan como emergencias de la «cosa» referida; es decir, fragmentos del discurso literal con el que puede ser descrita la lengua. Esta quiebra de las metáforas se corresponde en el juego con la estrategia que los clásicos usaron para caracterizar a las adivinanzas: una proposición que oculta y otra que revela. Los enunciados adivinatorios son así peculiares combinaciones de fragmentos discursivos forjados en códigos distintos.

Como son dos discursos entrelazados para formar uno solo, en todo caso, la solución una vez dicha rompe toda construcción alegórica formada sobre ella. Las soluciones disuelven, así, las metáforas. El enunciado adivinatorio alegórico para el que acepta descifrarlo produce la impresión de que se desbarata como castillo de naipes cuando se proporciona la solución. La realidad transformada por la maravilla de la metáfora torna entonces a su condición de cosa vulgar y cotidiana.

Hay un modo metafórico cultivado en las adivinanzas que explota de forma peculiar la referencia inscrita en los enunciados, amparado, también, bajo el código lúdico. Discursos de aparente contenido sexual, por otra parte, tabuizado en las conversaciones cotidianas, se ofrecen como oportunidades para una subversión descargada de intención, puesto que la referencia y, por tanto, el contenido «real»son siempre inocentes y cotidianas «cosas». Recordaba Huizinga que estos enunciados se encuentran en el Atharbaveda (2007: 139). En la colección citada de G. Correas y, también, en las colecciones actuales, aparece lo siguiente:

Mi tía está tendida,

mi tío va y viene

y metido se lo tiene.

La glosa de Correas declara la solución: «La artesa y el puño, entrando y saliendo de la masa hiñendo» (1967: 553). Acciones diferentes como echar el pestillo a la puerta:

Detrás de la puerta

lo ví hacer,

sacar y meter, 
meter y sacar
y dar de barriga
y no es picardía.

Otra como montar a caballo:

Gordo lo tengo, más lo quisiera, que entre las piernas no me cupiera.

O comprar una lechuga:

Fui a la plaza, compré una moza, le alcé la saya y le vi la cosa.

También meter un bizcocho en el café:

Duro lo meto, lo saco blando y por la puntita chorreando.

O poner un anillo en el dedo:

\author{
Por un gusto \\ un disgusto, \\ por el gusto de una mujer, \\ por un agujero justo, \\ entra carne sin cocer. \\ $\mathrm{O}$ avivar un candil: \\ Un hombre muy chiquinino, \\ con el culo en la pared \\ y la cocina tiesa, \\ esperando a la mujer.
}

Son transformadas siguiendo direcciones metafóricas (o usando términos genéricos, un modo eufemístico de designar órganos y acciones sexuales) que toman coimplicados términos explícita o alusivamente relativos al sexo. Por el juego, el lenguaje sexual está relativamente destabuizado. Los niños profieren estas adivinanzas a veces con cierta osadía cuando lo hacen ante los adultos y con intencionada voluntad de transgresión cuando lo hacen ante sus compañeros. Es tan obvio que se está hablando de sexualidad, que los que intervienen en el juego descartan enseguida que las soluciones pertenezcan a ese ámbito. Ocurre, sin embargo, que en la medida en que la emisión pública de las palabras esté tabuizada, se busque decirlas. El tabú opera funcionalmente en la línea de la criptificación. De modo que este tipo de enunciados adivinatorios tiene soluciones a dos niveles. Una en el dominio de la sexualidad y otra en el dominio de las acciones 
cotidianas del trabajo, la comida, entre otras. El propio enunciado y la solución en términos de sexualidad rompen el tabú.

Las soluciones del segundo nivel parecen coartadas. Este uso subversivo de las metáforas procede en un doble rizo. Las analogías de la sexualidad suelen apoyarse en diversos rasgos - subsumidos en términos - de objetos o acciones en la vida cotidiana y permiten hablar de ella de modo elíptico y según sobreentendidos. Los enunciados adivinatorios invierten la dirección metafórica, puesto que retoman el lenguaje de los sobreentendidos, gracias a que, en todo caso, no se mueve en la literalidad, sino con alusiones para volverle en referencia a objetos y acciones. En este sentido, las adivinanzas es un juego con formas carnavalescas.

No solo se actúa subversivamente a través de las oposiciones y de las metáforas. Otras figuras como la hipérbole lo permiten con igual eficacia. Las hipérboles tienen su campo de ejercicio especialmente en un subtipo de adivinanzas conocido como «colmos» y en otros subtipos de dichos equivalentes como los «tantanes»; por ejemplo: «Era un hombre tan gordo, tan gordo que para abrocharse el cinturón tenía que dar un paso adelante», «Era un hombre tan alto, tan alto que para hablar con él había que hacer noche en su ombligo», «Era un hombre tan delgado, tan delgado que se ponía un traje de mil rayas y le sobraban novecientas noventa y nueve», entre otras. Con estos y con otros tipos adivinancísticos, la probabilidad de que quien formula la pregunta dé igualmente la respuesta es muy alta. Se aproximan a los chistes, aunque se mantienen algunas reglas del juego, puesto que quien plantea la pregunta espera - al menos un instante - de su audiencia alguna respuesta, antes de precipitarse a dar la solución. Los colmos tienen, generalmente, como sujeto de referencia los seres humanos en sus papeles sociales (que, sin embargo, casi nunca lo son de los enunciados adivinatorios). Los colmos son una exploración de lo extremo (equivalentes en intensidad a una hipérbole), moviéndose en distintas direcciones, hacia lo absurdo, hacia la parodia, hacia lo sorprendente, por ejemplo:

¿Cuál es el colmo de un zapatero?

Tener el pelo cortado al cepillo y una pata de palo o tener un hijo listón, una hija traviesa, un hermano madero y un perro que mueva la cola.

¿Cuál es el colmo de un bombero?

Apagar un fuego con la manga de un chaleco.

¿Cuál es el colmo de un geógrafo?

Tener un hijo cabo y el otro golfo.

Las hipérboles revelan hasta qué punto la exploración de lo extremo es uno de los procedimientos de la criptificación. El lenguaje tiene recursos análogos a lentes o espejos, cuya estructura devuelve imágenes desfiguradas. Además, la pregunta sobre lo extremo implica un punto de partida en un desplazamiento. No obstante y presumiblemente, hay numerosas direcciones posibles, por lo que la respuesta «adecuada» no es fácil, sino relativamente impredecible, a no ser que haya sido oída anteriormente en la misma clave. Asimismo, el «colmo» es progresivo, la respuesta puede no ser adecuada porque podría proporcionarse otra aún más extrema y los límites de lo extremo son casi indefinidos. El «colmo» es una forma paródica, pero no alcanza lo grotesco, lo monstruoso. Se juega con los dobles sentidos de términos y frases, con las paronomasias, con la ambigüiedad. La 
imagen de los papeles sociales que traduce no es tan satírica como lúdica y, en muchos casos, es sobre todo un juego con el lenguaje, como en:

¿Cuál es el colmo de un carpintero?

Serrar con Sierra Nevada la pata del Banco de España.

¿Cuál es el colmo de un cerero?

Hacer un cirio con la acera de enfrente.

Los subtipos de adivinanzas se extienden con los «queledijos», los «parecidos», las «diferencias», los «cálculos», algunos de ellos con trampa, las «preguntas de pega» y otro numeroso conjunto de preguntas de difícil clasificación. Como advirtió Brandes en Monteros todos ellos responden mejor al nombre de «acertijos», porque dado lo escueto de la pregunta es cuestión de acertar con la respuesta (1980: 130). Sin embargo, salvo los «cálculos», los problemas existenciales antes citados y alguna que otra cuestión - preguntas y respuestas - se dicen casi de seguido, no esperándose tanto que la audiencia acierte con la respuesta cuanto que el locutor haga alarde, al decirla, de ingenio, sentido del humor, capacidad de sorprender, dominio del lenguaje y de la situación. En algunos casos, efectivamente el objetivo no es solo dejar a la audiencia en la condición de inferioridad a causa de su ignorancia —o meramente buscar en ella admiración o algún reconocimiento-, sino que, aún más, se pretende la burla, «cazar» a alguien poco advertido y tan ingenuo como para suponer que el «juego» tiene sus reglas y que estas se siguen en todos los casos. Se riza el rizo cuando la pregunta que se formula cuenta con el saber de la audiencia, que, confiada, hace gala de él para recibir a continuación la sanción de «ignorante», porque hay otra respuesta mejor que se guardaba por mantener la superioridad que da el tener la última palabra, o para ser rematado con la burla. Entre las adivinanzas infantiles es clásica (y vieja) esta:

Adivina, adivinaja, ¿quién puso el huevo el paja? [Otra variante es: ¿Quién pone el huevo en la casa?]

La gallina.

Mierda para el que lo adivina.

Y esta otra que reproduce Brandes:

¿En qué se parecen una familia, un piloto y un salvaje?

¿En qué?

En que el piloto pilota un avión y el salvaje va en pilota

¿y la familia?

Muy bien, gracias.

Aunque lo parezca, las respuestas no son estrictamente arbitrarias, sino relativamente impredecibles. Este tipo de preguntas — que facilita la denuncia por parte de la audiencia tras una proposición que anuncia una relación entre tres términos, cuando solo se ha dado cuenta de la relación entre dos - muestra la existencia de reglas y la exigencia de su seguimiento. Con ello juegan ambos interlocutores. Quien ha preparado la burla, ha previsto la denuncia y la forma no solo de neutralizarla, sino de ridiculizar al denunciante. También, había advertido Huizinga que en los enigmas se encuentran diferentes enunciados para la misma cosa (1938: 137). En todo caso, en manos de los 
proponentes, las preguntas tienen una sola respuesta y «acertar» consiste en dar con ella. Entre los objetivos posibles del adivinar, el juego de las adivinanzas no trata de «adivinar el futuro», sino que, en parte, se trata de desvelar lo oculto y, sobre todo, de «adivinar el pensamiento». Un ejercicio continuo y necesario para la interacción social.

\section{SABER Y ADIVINAR}

No parece posible —o tal vez sea tarea inútil— lograr una clasificación precisa de los tipos y subtipos de adivinanzas, pero aún mantiene solidez la idea de algún componente común entre todos ellos, que Huizinga intuyó en Homo ludens cuando tituló el capítulo sobre los enigmas: «Juego y sabiduría» (2007: 137 y ss.). Hay muchas modalidades de preguntas y son muy diversos los grados de transcendencia y compromiso para los que se involucran en esos juegos, pero la división de papeles es constante, así como la situación de inestabilidad en sus posiciones respectivas. Las tonalidades del juego se ordenan entre el desafío y la exhibición, aunque todas tienen el color del poder.

Si cabe hacer alguna distinción en las formas, no tiene demasiada importancia si en las adivinanzas predomina un tipo u otro de estrofas o un tipo u otro de construcción fraseológica en prosa. Tampoco es determinante que las adivinanzas respondan o no en estructura a una definición. Si fuera así, entonces, cabrían dos tipos de preguntas: aquellas que contienen predicados y cuya respuesta apropiada es un sujeto, un nombre; y aquellas otras que contienen uno o varios sujetos y cuya respuesta apropiada es el o los predicados que les corresponden. No todas las adivinanzas son definiciones, pero, en términos generales, se perfila una distinción básica entre dos tipos de enunciados adivinatorios. Unos contienen explícita o implícitamente elementos suficientes para obtener con ellos y a partir de ellos la solución. De manera que tal solución es más bien re-conocimiento. Hay, además, otros enunciados que requieren como información necesaria elementos que no se hallan en ellos para dar con la solución. Estas otras soluciones aparentemente amplían el conocimiento, aunque, una vez proporcionadas, tal vez se descubra que también son un re-conocimiento.

Las adivinanzas no son adivinaciones, no obstante, es un juego del saber. Este juego ofrece dos papeles complementarios, puesto que el contenido del juego (el discurso integrado por preguntas y respuestas) solo se completa y cierra con la intervención de ambos. Tales papeles no son teóricamente equivalentes, pero como posiciones no están ni al comienzo ni al final en el mismo nivel de igualdad. En el momento de partida, el que pregunta está en una posición de superioridad, porque se supone que también conoce la respuesta. El juego termina con la superioridad del que responde, sea ése el que el que aceptó la pregunta o el mismo que la planteó. Las adivinanzas pueden tener varias «respuestas», pero solo tienen una única «solución». Es «solución» y no tanto «respuesta» porque a veces pone fin a una contienda, otras veces es una salida a una situación de dependencia que se percibe como liberación, otras es un acto de generosidad y otras un fallo, una sentencia. El juego no versa sobre maravillas ignotas, sino sobre el entorno inmediato, cotidiano, archiconocido, habitual, que es transformado por arte retórica, por politropía, y con ingenio, humor, alguna dosis de ironía o de osadía y espíritu transgresor, hasta hacerlo relativamente irreconocible.

El juego otorga a los participantes la posibilidad de mostrar en confrontación o en exhibición su saber: unos lo hacen presentando la imagen de un mundo tan artificiosamente transformado que se torna casi irreconocible; los otros, mostrando su capacidad de hacerlo reconocible, pese a tanto artificio. El saber aparentemente consiste en tener las soluciones, lo que se consigue con memoria y estando dispuesto a ser 
audiencia dependiente de otros hasta adquirirlas. Al menos, durante la etapa infantil, no es una estrategia, es una situación obligada. La mayoría de los jugadores no son creadores de adivinanzas, sino reproductores. En los contextos clásicos, la creación se atribuye a narradores venidos de lejanas tierras que proponen como adivinanzas descripciones de acontecimientos sucedidos en el camino. El sentido de la maravilla en los antiguos relatos de viajeros parece asociado al de adivinanza. Pero sobre el entorno inmediato y cotidiano no parece caber muchas sorpresas.

El saber no está en la experiencia y conocimiento proporcionado por acontecimientos maravillosos o extraños, sino que está sobre todo en el conocimiento y uso de los procedimientos de transformación y criptificación del entorno. Los principales medios han sido antes analizados: la elipsis, las oposiciones y contrastes, las metáforas, las hipérboles, entre otras. Desde esta perspectiva, la elipsis supone un mundo fragmentado, desagregado, parcialmente percibido, y el saber, utilizando esos fragmentos, consiste en recomponerle, completarle, percibirle en conjuntos, agrupaciones, unidades y totalidades. Las oposiciones y contrastes revelan un mundo desordenado, amenazante por contradictorio, cerrado, caótico, y el saber consiste en restablecer el orden, recolocar las cosas en su sitio, encontrar salidas a dilemas y situaciones comprometidas.

Las metáforas y alegorías revelan un mundo fluido, deslizante en direcciones diversas e impredecibles, y el saber consiste en descubrir esas direcciones, en reconstruirle a otro nivel, en recrearle constantemente. $Y$ en todo caso el saber consiste en el dominio del lenguaje, aunque el juego discurre a la vez como interacción social. El saber es al mismo tiempo estrategia en el campo de la confrontación, inestabilidad de las posiciones respectivas y ejercicio del poder. Los procedimientos de criptificación se revelan como estrategias para establecer y mantener dependencia, para liberarse, para invertir las posiciones. Las estrategias revelan cómo, desde una posición superior, la dependencia de otros se logra y mantiene otorgando el conocimiento y la información en dosis (fragmentariamente) o presentando las situaciones como dilemas sin opción posible o reelaborándolas imaginativamente desafiando al sentido común o exigiendo el conocimiento de códigos especiales de interpretación. Desde una posición inicial de dependencia, las estrategias están dirigidas a obtener toda la información, a derruir falsas barreras, a explorar todas las direcciones y, al fin y al cabo, no solo a liberarse, sino a elevarse, a cambiar a mejor posición.

Todo esto se entrelaza con las posiciones estructurales de desigualdad de los géneros (varones y mujeres), de los grupos de edad o de los estratos sociales. El juego del saber adquiere, entonces, otros objetivos. Sin embargo, las adivinanzas muestran que el saber consiste en emplear el lenguaje para engañar y para no dejarse engañar, para burlarse de otros y para no dejar que otros se burlen de uno, para estrechar vinculaciones y para desembarazarse de ellas. Como dicen muchas expresiones populares, el saber consiste tanto en «no quedar por tonto» como en «no pasarse de listo»; en «cazarlas al vuelo» y en «tener los ojos bien abiertos»; en «leer entre líneas» y en «entender sin necesidad de muchas palabras»; en «separar el grano de la paja»; en «dorar la píldora»; en «tener respuesta para todo», entre otros. En fin, las adivinanzas son un buen ejercicio del habla y de la mente en sociedad. 


\section{BIBLIOGRAFÍA}

Abrahams, R. D. y Dundes, A. (1972): «Riddles», en Folklore and Folklife, R.M. Dorson (ed.), Chicago, Chicago University Press, pp. 129-143.

ARISTÓTELES (1999): Retórica. Introducción, traducción y notas de Quintín Racionero. Madrid, Gredos.

BAJTín, M. (1965): La cultura popular en la Edad Media y Renacimiento, Barcelona, Barral editores (1974).

Bajtín, M. (1990): The Dialogic Imagination. Four Essays. M. Holquist (ed.), C. Emerson y M. Holquist (trads.), Austin, University of Texas Press.

BAssols, M.M. (1991): L'enigmistica popular. Aproximació a los endevinalles catalanes, Valencia, Universitat de Valencia, Servei de Publicacions.

Beuchat, P.D. (1957): «Riddles in Bantu», en The Study of Folklore, A. Dundes (ed.), Englewood Cliffs, Prentice-Hall, Inc, pp. 182-205.

BRANDES, S. (1980): Metaphors of Masculinity. Sex and Status in Andalusian Folklore. The University of Pennsylvania Press.

DOI: https://doi.org/10.9783/9780812292503

CERvantes, Miguel de (1584): La Galatea, Edición de Juan Montero. Real Academia Española, 2004.

CROCKER, CH. (1977): «The Social Functions of Rhetorical Forms», en The social use of Metaphor. Essays on the Anthropology of Rhetoric. David Sapir y Christopher Crocker (eds.), University of Pennsylvania Press, pp. 33-66.

DOI: https://doi.org/10.9783/9781512806632-003

FERNÁNDEZ, J. (1974): «The mission of the metaphor in the expressive culture», Current Anthropology, 15, pp-119-145. DOI: https://doi.org/10.1086/201450

FERnÁNDEZ, J. (ed.) (1991): Beyond Metaphor. The theory of tropes in anthropology, Stanford, Stanford University Press.

Friedrich, P. (1991): «Polytropy», en Beyond Metaphor. The theory of tropes in anthropology, J. Fernandez (ed.), Stanford, Stanford University Press, pp. 17-55.

GeOrges, R. A. y Dundes, A. (1963): «Toward a structural definition of the riddle», Journal of American Folklore, pp. 111-118. DOI: https://doi.org/10.2307/538610

HuIZINGA, J. (1938): Homo ludens. Essai sur la fonction sociale du jeu, Paris, Gallimard. Edición española: Homo ludens. Madrid, Alianza Editorial, 2007.

JAKOBSON, R. (1963): Essais de Linguistique générale. Paris, De Minuit.

KÖNGAS MARANDA, E. (1969): «Structure des enigmes», L'Homme, 3, pp. 5-48. DOI: https://doi.org/10.3406/hom.1969.367052

KÖNGAS MARANDA, E. (1971a): «The logic of riddles», en Structural Analysis of Oral Tradition, University of Pennsylvania Press, pp. 189-232.

DOI: https://doi.org/10.9783/9781512804393-009

KÖNGAS MARANDA, E. (1971b): «A tree grows. Transformations of a riddle metaphor», en Structural Models in Folklore and Transformational Essays, E. Köngas Maranda y P. Maranda (eds.), The Hague, Mouton, pp. 116-145.

DOI: https://doi.org/10.1515/9783110900552-004

Machado y Álvarez, A. (1879): «Las adivinanzas. Apuntes para un estudio», La Enciclopedia, 15 de febrero, 15 de mayo, 15 de agosto, 25 de agosto. 
MiAJA DE LA PeÑA, M. ${ }^{\text {a }}$ T. (2005): «La adivinanza, sentido y pervivencia», Acta poética 26, pp. 1-2, pp. 443-463. DOI: https://doi.org/10.19130/iifl.ap.2005.1-2.178

PÉREZ DE HERRERA, Cristóbal (1733). Proverbios morales y consejos christianos. Madrid, Herederos de Francisco del Hierro.

PÉREZ VidAL, J. (1953): «Dos notas al libro de Apolonio», Revista de Dialectología y Tradiciones Populares, IX, pp. 90-94.

PÉREZ VIDAL, J. (1986): Folclore infantil canario, Madrid, Excmo. Cabildo Insular de Gran Canaria. LC.E.F.

QuinN, N. (1991): «The Cultural Basis of Metaphor», en Beyond Metaphor, The theory of tropes in anthropology, J. Fernandez (ed.), Stanford, Stanford University Press, pp. 56-93.

Redondo, A. (1980): «Le jeu de l'enigme dans l'Espagne du XVI siecle et du début du XVII siecle. Aspect ludique et subversion», en Les fêtes de la Renaissance. Actes du XIII Colloque International d'Etudes Humanistes, Paris, Vrin, 1982, pp. 445458.

SAPIR, D. (1977): «The Anatomy of Metaphor», en The social use of Metaphor. Essays on the Anthropology of Rhetoric, David Sapir y Christopher Crocker (eds.), University of Pennsylvania Press, pp. 3-32.

DOI: https://doi.org/10.9783/9781512806632

ScOTT, CH. T. (1969): «On defining the riddle: the problem of a structural unit», Genre, 2, pp. 129-142.

Todorov, T. (1978): Los géneros del discurso, Caracas, Monte Ávila editores, 1996.

VELASCO, H. M. (1983): «Sobre los procesos de la tradición oral: las adivinanzas, mediaciones de poder y de saber», en Culturas populares. Diferencias, divergencias, conflictos, Coloquio Hispano-Francés, Madrid, Casa de Velázquez, Universidad Complutense, pp. 171-184.

VelasCO, H. M. (1985): «Categorías, definiciones, desafíos y adivinanzas», en Actas del II Congreso de Antropología, Madrid, Ministerio de Cultura, pp. 375-383.

Colecciones de adivinanzas en español, catalán, gallego, euskera:

Amades, J. (1934a): Diccionari d'endevinalles, Barcelona, La Neotípia.

AMADES, J. (1934b): Enigmes populars, Barcelona, La Neotípia.

AZKUE, R. M. de (1945): Euskalerrien Yakintza, Madrid, Espasa Calpe

CABALLERO, F. (1877): Adivinanzas, acertijos y refranes populares, Selección y prólogo de C. Bravo-Villasante, Madrid, Montena, 1989.

CAStañón, L. (1961): «Cosadielles de Asturias», Revista de Dialectología y Tradiciones Populares, XVII, pp. 561-570.

CERrillo, P. (2000): Adivinanzas populares españolas. Estudio y antología, Cuenca, Ediciones de la Universidad de Castilla-La Mancha.

CORREAS, G. (1627): Vocabulario de refranes y frases proverbiales. Edición de L. Combet en l'Institut d'etudes ibériques et ibéro-américaines de l'Université de Bordeaux, 1967.

Cuscoy, L. D. (1944): Folklore infantil, Tenerife, Inst. de Estd. Canarios.

DEMÓFILO (1883): Colección de enigmas y adivinanzas en forma de diccionario, Sevilla. DURÁN, P. (1952): Las 300 mejores adivinanzas del idioma castellano, Lima, Edit.Durán. EsPinOSA, A. M. (1952): «Algunas adivinanzas españolas», Revista de Dialectología y Tradiciones Populares, VIII, pp. 31-66 
GARFER, J. L. y FERNÁNDEZ, C. (1983): Adivinancero popular español, Madrid, Taurus. GARFER, J. L. y FERNÁNDEZ, C. (1989): Acertijero popular español, Madrid, Fundación Banco Exterior.

JIJENA, R. (1948): Adivina, adivinador. 500 de las mejores adivinanzas de la lengua española, Buenos Aires, Albatros.

LEHMANN-NitsCHE, R. (1911): Adivinanzas rioplatenses, Buenos Aires, Imp. Covi Hermanos.

MARTIN, P. (1985): ¿Que cousa é cousa? Libro das adiviñas, Vigo, Galaxia.

Milla, Ll. (1965): 1000 endevinalles catalanes amb les seves solucions, Barcelona, Milla.

Milla, Ll. (1990): Segon lliebre d'endevinalles, Barcelona, Milla.

MORÁN, C. (1957): «Acertijos. Colección recogida directamente del pueblo», Revista de Dialectología y Tradiciones Populares, XIII, pp. 299-364.

Pelay, F. (1882): Endevinallas populares catalanas, Barcelona, Lib. d'Eduald Puig.

RodríGUEZ MARÍn, F. (1882-1883): Cantos populares españoles, Sevilla, Francisco Romero y Cía.

Fecha de recepción: 29 de agosto de 2019

Fecha de aceptación: 2 de septiembre de 2019

$$
\text { 9 }
$$

